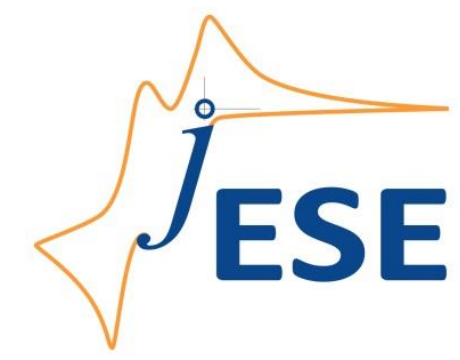

Open Access : : ISSN 1847-9286

www.jESE-online.org

Original scientific paper

\title{
Mathematical modeling and reliability analysis of a 3D Li-ion battery
}

\author{
RICHARD HONG PENG LIANG, TANGSHENG ZOU, KARTHIK SOMASUNDARAM*凶, \\ WEI TONG*, ERIK BIRGERSSON**
}

Raffles Science Institute, Raffles Institution, One Raffles Institution Lane, Singapore 575954

*Department of Mechanical Engineering, National University of Singapore, Singapore 117576

**Department of Chemical and Biomolecular Engineering, National University of Singapore, Singapore 117576

${ }^{\square}$ Corresponding Authors: E-mail: vivekarthik81@yahoo.co.in; Tel.: +65-6516 4657; Fax: +65-6779 1936 Received: July 24, 2013; Revised: October 24, 2013; Published: January 25, 2014

\begin{abstract}
The three-dimensional (3D) Li-ion battery presents an effective solution to issues affecting its two-dimensional counterparts, as it is able to attain high energy capacities for the same areal footprint without sacrificing power density. A 3D battery has key structural features extending in and fully utilizing 3D space, allowing it to achieve greater reliability and longevity. This study applies an electrochemical-thermal coupled model to a checkerboard array of alternating positive and negative electrodes in a 3D architecture with either square or circular electrodes. The mathematical model comprises the transient conservation of charge, species, and energy together with electroneutrality, constitutive relations and relevant initial and boundary conditions. A reliability analysis carried out to simulate malfunctioning of either a positive or negative electrode reveals that although there are deviations in electrochemical and thermal behavior for electrodes adjacent to the malfunctioning electrode as compared to that in a fully-functioning array, there is little effect on electrodes further away, demonstrating the redundancy that a 3D electrode array provides. The results demonstrate that implementation of $3 D$ batteries allow it to reliably and safely deliver power even if a component malfunctions, a strong advantage over conventional 2D batteries.
\end{abstract}

\section{Keywords}

3D batteries, Li-ion battery, mathematical model, reliability analysis, thermal model 


\section{Introduction}

The demand for small scale, high power density sources has increased with the advent of miniaturized electronic devices such as micro-electromechanical systems (MEMS), micro-robots, micro-sensors and implantable medical devices. The lithium-ion battery is considered as a viable energy storage system that can cater to many of these applications, as it is able to attain the high energy densities required.

Conventional batteries with planar cathode and anode layers arranged in a parallel-plate configuration with a separator in between are known as two-dimensional (2D) cells, in which transport of Li-ions between the electrodes is one-dimensional (1D) in nature. This 2D cell currently used in commercial applications still face several constraints, especially regarding power limitations [1-3] and reliability which affect millions of industrial and small-scale consumers [4,5].

As a result, three-dimensional (3D) architectures have been developed for the lithium-ion battery $[1,3,6]$ partly to ameliorate some of these concerns and further harness its potential as a key energy solution for the future. This nascent concept describes cells with key structural features extending in and fully utilizing 3D space. As shown in Fig. 1a, a 3D cell typically consists of anodes and cathodes which have active surface areas exposed in three dimensions in closely-spaced arrays in a 2D plane. With this, we have to reconsider the phenomena of mass and charge transport, electronic and ionic conductivity and electron-transfer kinetics in the form of 3D batteries.

The 3D cell promises many benefits: it can attain enhanced energy capacity without compromising on power density, while maintaining the same areal footprint [6-8]; it enables us to take advantage of more extensive interactions between the active materials $[1,9,10]$, allowing us to adopt a design that improves reliability in the event that an active component ceases to function. The flow of energy and current in the conventional parallel-plate design essentially stops when an intermediate component fails. On the other hand, even if one of the electrodes in a 3D design fails, the battery can potentially continue to operate (albeit with reduced capacity and performance) as repeating units of electrodes arranged in a tessellation can provide redundancy.

Experiments have been able to produce working precursors to fully functional 3D batteries through the use of a variety of electrochemical deposition techniques. For instance, C-MEMS (Carbon-Microelectromechanical Systems), [11-13] a solution for miniaturization, uses photolithography to implement photoresist arrays on a $\mathrm{SiO}_{2}$ surface, followed by pyrolysis at high temperatures in an oxygen-free environment. Changing conditions under which these steps are carried out allows one to vary design shapes, and also mechanical and transport properties $[2,9,14,15]$. Lithographic techniques vapour deposition techniques are being used to prepare independent arrays of the electrodes [1,2,16-21]. Recently, interdigitated Li-ion microbatteries are prepared using 3D printing techniques [22].

However, computational studies and mathematical modelling have yet to be entirely developed for the 3D Li-ion cell, as they either do not completely solve for coupled electrochemistry, transport phenomena and heat generation, or consider only electrochemical phenomena for optimization studies. Hart et al. [6] modelled and estimated current densities and potentials for arrays of electrodes with different geometries, while Zadin et al. [23-25] focused on simulating the ionic transport mechanisms in liquid and polymer electrolytes inside a 3D microbattery assuming non-porous solid electrodes to show how cell geometry can give rise to qualitatively non-uniform current densities and thus suboptimal surface utilization. However, neither model considers the electrochemical activity or thermal behaviour inside the electrodes. On the other hand, detailed 
mathematical models have been formulated to predict transient local electrochemical and thermal changes in a Li-ion cell in a rectilinear geometry [26-29] and a spiral-wound geometry [30,31], both essentially 2D-collapsible geometries.

By virtue of the lack of a detailed resolution for modelling and simulation of coupled electrochemistry, transport phenomena and heat generation for the 3D Li-ion cell, the aim of this paper is twofold: First, to employ a thermal-electrochemical model for studying the behaviour of a 3D liquid electrolyte Li-ion cell applicable to various geometries; second, to apply this model to a planar tessellated electrode geometry and conduct a reliability analysis to demonstrate the redundancy and longevity that a 3D battery can attain. Our mathematical model will investigate the transient conservation of charges, species and energy; it couples the electrochemical and thermal behaviour through the heat generation arising from reversible, irreversible and ohmic heating as well as through the temperature-dependent transport and electrochemical parameters.

\section{Mathematical Formulation}

The 3D battery has the advantage of having a larger areal energy capacity than the conventional 2D design, but also has a disadvantage of having non-uniform current density. This would lead to the poor utilization of the electrode materials, resulting in lower cell efficiency, non-uniform heat dissipation etc. Studies have shown that a checkerboard cathode/anode array configuration, where each electrode is surrounded by four nearest neighbour opposite electrodes, provides a more uniform current output around every electrode compared to that of other arrays. Current uniformity in this 3D design would render it more useful in a wider variety of applications [6].

As a result, we have selected a 3D battery that consists of positive and negative electrodes arranged in square planar tessellation as shown in Fig. 1 for our study. Each electrode is adjacently bounded by four electrodes of opposite sign. Current collectors plates are present at either end of the electrodes; one for the anode and another for the cathode.

For the individual electrodes, we consider two shapes of different extremes - circles and squares. Square electrodes provide a cleaner tessellation in the array, shorter average distances between electrodes and a higher packing efficiency. Circular electrodes are however much more feasible to implement and representative of real-life manufacturing processes. Hence, we consider both the square and circular electrode arrays in this paper, and compare the differences in performance between these two extremes.

In order to ensure that the comparison between both square and circular arrays is fair, a few restrictions have been imposed. The minimum distance between each electrode $\left(w_{\text {se }}\right)$, as well as the thickness of both electrodes $\left(w_{\text {pe }}, w_{\text {ne }}\right)$ i.e. the diameter of the circular cross-section or the edge length of the square cross-section, is kept constant in both arrays. The dimensions are provided in Tables 1 and 2.

The electrochemical and thermal behaviour of a three-dimensional (3D) Li-ion cell consisting of a graphite negative electrode (ne) and a manganese oxide spinel positive electrode (pe) as shown in Fig. 1 is studied. The electrodes and the spaces between the electrodes are filled with an electrolyte solution (el) of $\mathrm{LiPF}_{6}$ salt in 1:2 ethylene carbonate: dimethyl carbonate solvent. The materials considered here are the same as that used for a conventional cell that is commercially available with the assumption that these can be utilized to fabricate 3D batteries using the conventional techniques.

As depicted in Fig. 1, there are two main scales involved in the modeling of a Li-ion cell: the macro- and the micro-scale. In short, the transport of ions and electrons in the cell between the 
electrodes is referred as the transport at the macroscale, which includes species transport in the liquid electrolyte, electronic charge conduction in the solid phase and ionic charge conduction in the liquid electrolyte; and the diffusion of ions in the active material present in the electrodes is referred to as transport at the microscale, which includes diffusion of lithium in the active material of the porous electrodes.

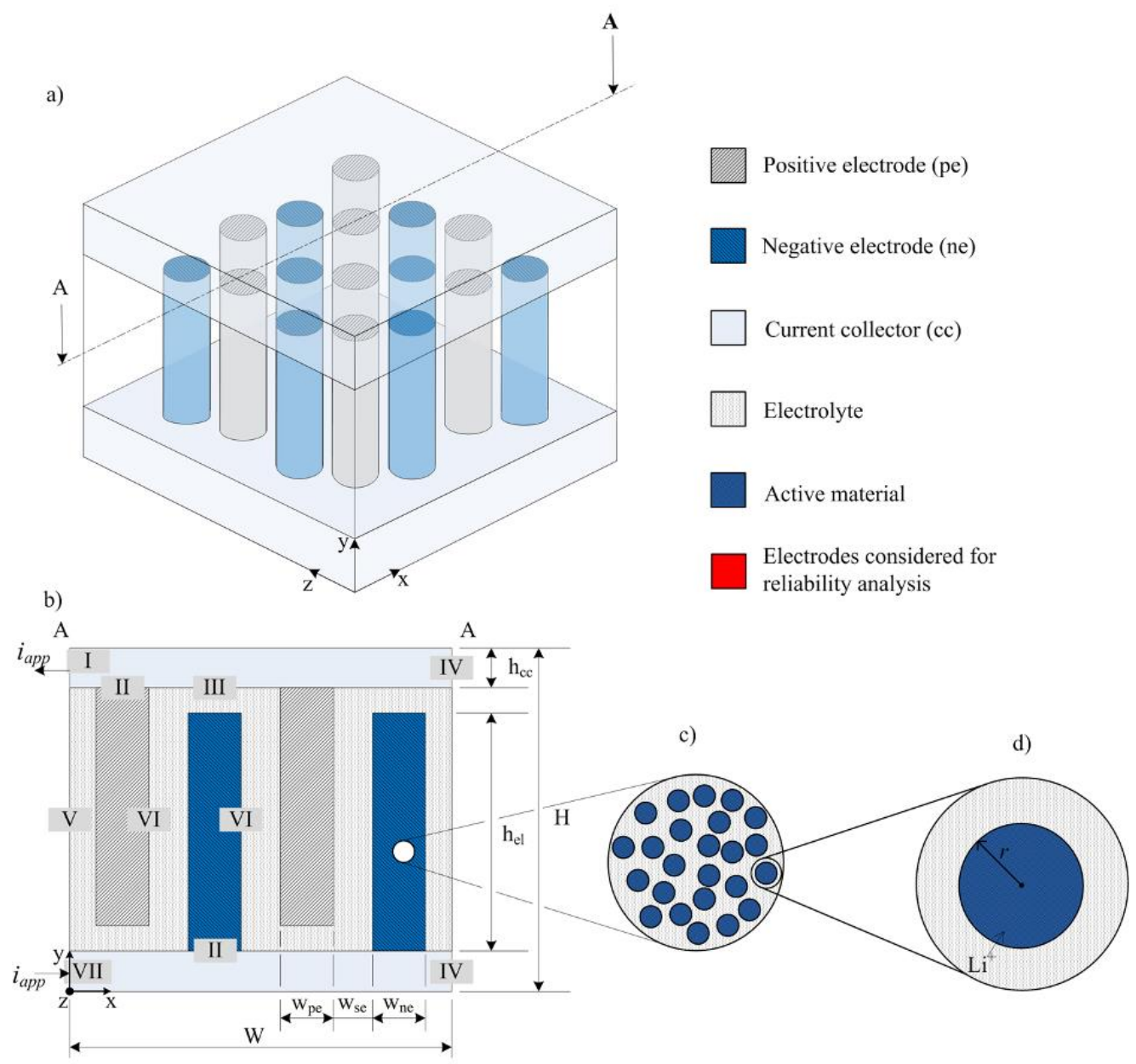

e)

f)

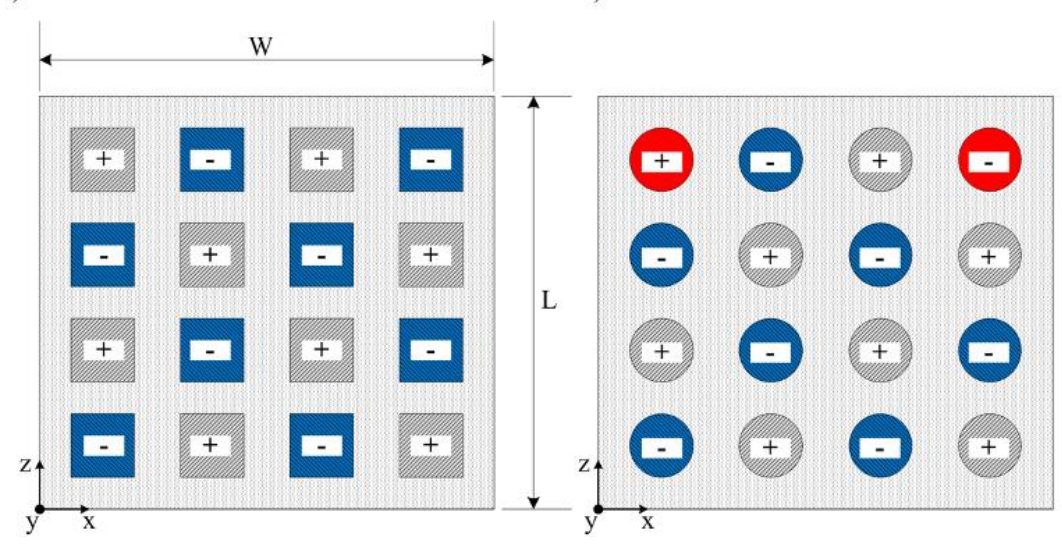

Figure 1. (a) Schematics of (a) 3D Li-ion battery, (b) section AA showing the various functional layers in the battery with the roman numerals indicating the interfaces of these layers and the boundaries, (c) agglomerate structure in the negative electrode (positive electrode also exhibits similar structure), (d) diffusion of lithium in active material in the electrodes on the microscale, (e) top view of the battery (xz-plane) with square cross-section, and (f) circular cross-section 
Table 1. Physical properties and design parameters of battery components

\begin{tabular}{|c|c|c|c|c|c|c|c|}
\hline Parameter & Unit & $\operatorname{cc}(-)$ & ne & el & pe & cc (+) & Ref. \\
\hline$c_{1}^{0}$ & $\mathrm{~mol} \mathrm{~m}^{-3}$ & - & \multicolumn{3}{|c|}{$2.0 \times 10^{3}$} & - & 27 \\
\hline$C_{p}$ & $\mathrm{~J} \mathrm{~kg}^{-1} \mathrm{~K}^{-1}$ & $3.8 \times 10^{2}$ & $7.0 \times 10^{2}$ & $7.0 \times 10^{2}$ & $7.0 \times 10^{2}$ & $8.7 \times 10^{2}$ & 34,37 \\
\hline$c_{s}^{0}$ & $\mathrm{~mol} \mathrm{~m}^{-3}$ & - & $1.5 \times 10^{4}$ & - & $3.9 \times 10^{3}$ & - & 27 \\
\hline$c_{s}^{\max }$ & $\mathrm{mol} \mathrm{m}^{-3}$ & - & $2.6 \times 10^{4}$ & - & $2.3 \times 10^{4}$ & - & 27 \\
\hline$D_{1}$ & $m^{2} s^{-1}$ & - & \multicolumn{3}{|c|}{$7.5 \times 10^{-11}$} & - & 27 \\
\hline$D_{\mathrm{s}}$ & $m^{2} s^{-1}$ & - & $3.9 \times 10^{-14}$ & - & $1.0 \times 10^{-13}$ & - & 27 \\
\hline$E_{\mathrm{a}, \mathrm{D}_{\mathrm{i}}}$ & $\mathrm{kJ} \mathrm{mol}^{-1}$ & - & \multicolumn{3}{|c|}{10} & - & 34 \\
\hline$E_{\mathrm{a}, \mathrm{D}_{\mathrm{s}}}$ & $\mathrm{kJ} \mathrm{mol}^{-1}$ & - & 4 & - & 20 & - & 34 \\
\hline$E_{a, \sigma_{l}}$ & $\mathrm{~kJ} \mathrm{~mol}^{-1}$ & - & \multicolumn{3}{|c|}{20} & - & 34 \\
\hline$h_{\mathrm{i}}$ & $\mathrm{m}$ & $10 \times 10^{-6}$ & $5 \times 10^{-4}$ & - & $5 \times 10^{-4}$ & $10 \times 10^{-6}$ & - \\
\hline$k$ & $\mathrm{~W} \mathrm{~m}^{-1} \mathrm{~K}^{-1}$ & $3.8 \times 10^{2}$ & $0.05 \times 10^{2}$ & $0.01 \times 10^{2}$ & $0.05 \times 10^{2}$ & $2.0 \times 10^{2}$ & 34,37 \\
\hline$k_{0}$ & $\mathrm{~mol}^{2.5} \mathrm{~m}^{-0.5} \mathrm{~s}^{-1}$ & - & $2 \times 10^{-11}$ & - & $2 \times 10^{-11}$ & - & - \\
\hline$R_{\mathrm{s}}$ & $\mathrm{m}$ & - & $12.5 \times 10^{-6}$ & - & $8.5 \times 10^{-6}$ & - & 27 \\
\hline$W_{\mathrm{i}}$ & $\mathrm{m}$ & - & $10 \times 10^{-5}$ & - & $10 \times 10^{-5}$ & - & - \\
\hline$\alpha_{\mathrm{a}}, \alpha_{\mathrm{c}}$ & - & - & 0.5 & - & 0.5 & - & 27 \\
\hline$\varepsilon_{\mathrm{p}}$ & - & - & 0.14 & - & 0.19 & - & 27 \\
\hline$\varepsilon_{1}$ & - & - & 0.36 & - & 0.44 & - & 27 \\
\hline$\varepsilon_{\mathrm{f}}$ & - & - & 0.03 & - & 0.07 & - & 27 \\
\hline$\vartheta_{i}^{0}$ & - & - & 0.56 & - & 0.17 & - & 27 \\
\hline$\rho$ & $\mathrm{kg} \mathrm{m}^{-3}$ & $9.0 \times 10^{3}$ & $1.9 \times 10^{3}$ & $1.2 \times 10^{3}$ & $4.1 \times 10^{3}$ & $2.7 \times 10^{3}$ & $27,34,37$ \\
\hline$\sigma_{\mathrm{s}}$ & $\mathrm{S} \mathrm{m}^{-1}$ & $6.0 \times 10^{7}$ & $1.0 \times 10^{2}$ & - & 3.8 & $3.8 \times 10^{7}$ & 34 \\
\hline
\end{tabular}

Table 2. Other model parameters

\begin{tabular}{|c|c|l|}
\hline Parameter & Unit & Value \\
\hline$H$ & $\mathrm{~m}$ & $5.7 \times 10^{-4}$ \\
\hline$h_{\mathrm{t}}$ & $\mathrm{W} \mathrm{m}^{-2} \mathrm{~K}^{-1}$ & 5 \\
\hline$i_{\text {app }}$ & $\mathrm{A} \mathrm{m}^{-2}$ & $7 \times 10^{2}$ (circular); $9 \times 10^{2}$ (square) \\
\hline$L$ & $\mathrm{~m}$ & $6.6 \times 10^{-4}$ \\
\hline$T_{a} T_{\text {ref }}$ & $\mathrm{K}$ & 298.15 \\
\hline$W$ & $\mathrm{~m}$ & $6.6 \times 10^{-4}$ \\
\hline$W_{\text {se }}$ & $\mathrm{m}$ & $5.2 \times 10^{-5}$ \\
\hline
\end{tabular}

The model is based on the porous-electrode theory developed by Newman and Tiedemann $[32,33]$ and embodies the following main assumptions:

1. Isotropic material properties;

2. Uniform distribution of active materials of the same size in the electrodes;

3. The active material is assumed to be spherical; i.e., we only need to consider the radial direction at the microscale;

4. Side reactions are assumed negligible.

The mathematical formulation consists of the conservation equations of species and charge, together with conservation of energy at macroscale [27,34]; the diffusion length or the polynomial approximation approach is employed for the conservation of lithium inside the active material at microscale. For the sake of brevity, the governing equations, initial conditions, and constitutive relations are provided in tables in the appendix and the details can be found in our earlier work [31]. 
The physical properties and design adjustable parameters pertaining to the geometry studied in this work are given in Tables 1 and 2.

The current density is prescribed at the positive current collector at the boundary I (see Fig. 1b for placement of roman numerals) and also Newton's law of cooling is specified here. At the interface between the current collector/electrode or the current collecting tab/current collector, continuity of energy flux and solid-phase current is specified; insulation is specified for the ionic flux and current. At the current collector/electrolyte, insulation is defined for the solid phase current and continuity for the energy flux. At the boundaries IV and V, there is no flow of ions/electrons as well as energy and hence insulation is specified here as well for solid phase current and energy. At the electrode/electrolyte interfaces, continuity of energy flux and ionic flux as well as ionic current is defined and since there is no flow of electrons across the interface, insulation for solid phase current is defined. The current is collected from the negative current collector at the boundary VII or otherwise this end is grounded and also Newton's law of cooling is specified here.

\section{Numerics}

The commercial finite-element solver, COMSOL Multiphysics 3.5a [35], was employed to solve the 3D model. Linear elements were implemented for all dependent variables $\varphi_{\mathrm{s}}, \varphi_{\mathrm{l}}, c_{\mathrm{l}}, c_{\mathrm{s}}^{\text {surf }}, \mathrm{T}$ and $c_{s}^{\text {avg }}$ the direct solver UMFPACK was chosen as linear solver with a relative convergence tolerance of $10^{-4}$, and solutions for all models were tested for mesh independence. All computations were carried out on a workstation with dual-core processors $(2.33 \mathrm{GHz})$ and a total of $64 \mathrm{~GB}$ random access memory (RAM).

Charge and discharge currents, $i_{\mathrm{app}}$, were applied at the respective boundaries with a smoothed Heaviside function. For both $3 \mathrm{D}$ arrays, there were $3 \times 10^{4}$ elements and $1.6 \times 10^{5}$ degrees of freedom (DoF) which required around 45 GB of memory for solution under $5 \mathrm{C}$ discharge with a solution time of around $1 \mathrm{hr}$. The reliability analysis was carried out by targeting one of the electrodes - either positive or negative - as marked in our computational cell in Fig. 1f. We assume that there will be no exchange current in the malfunctioning electrode as no reaction occurs; to reflect this, the transfer current per unit volume, $J$, is set to zero in the simulation for that electrode alone.

\section{Results and Discussion}

In this section, we begin by studying the behaviour during discharge of a 3D lithium-ion battery with tessellated electrode geometry, for both the square and circular electrode arrays. A reliability analysis is then carried out for the circular electrode array to study the behaviour of the battery when one of the electrodes in the array malfunctions. Only the discharge process will be illustrated as charging exhibits a similar behaviour.

\section{Standard Discharge Behaviour}

\section{Discharge curves}

First, we shall explore the global behaviour of the 3D battery in terms of potential during discharge for different C-rates, as shown in Fig. 2. The drop in cell voltage during the discharge in both the square and circular electrode arrays is similar. Both arrays exhibit a gentle and constant decrease in potential for most of the discharge period except for the sharp drop towards the end of discharge, similar to that of the 2D cell. Under all discharge rates, there is a sudden drop in the 
potential from the initial value of $4.2 \mathrm{~V}$ during the initial period of discharge that corresponds to ohmic losses. At $1 \mathrm{C}$-rate, there is a gradual drop in the potential from $3.9 \mathrm{~V}$ to $3 \mathrm{~V}$ until the end of discharge at $3600 \mathrm{~s}$ when a sudden drop in the potential is seen as in Fig. 2. While a similar trend is observed for discharge at 2 C-rate, the array experiences a much faster drop in potential at 5 C-rate due to a higher discharge current density.

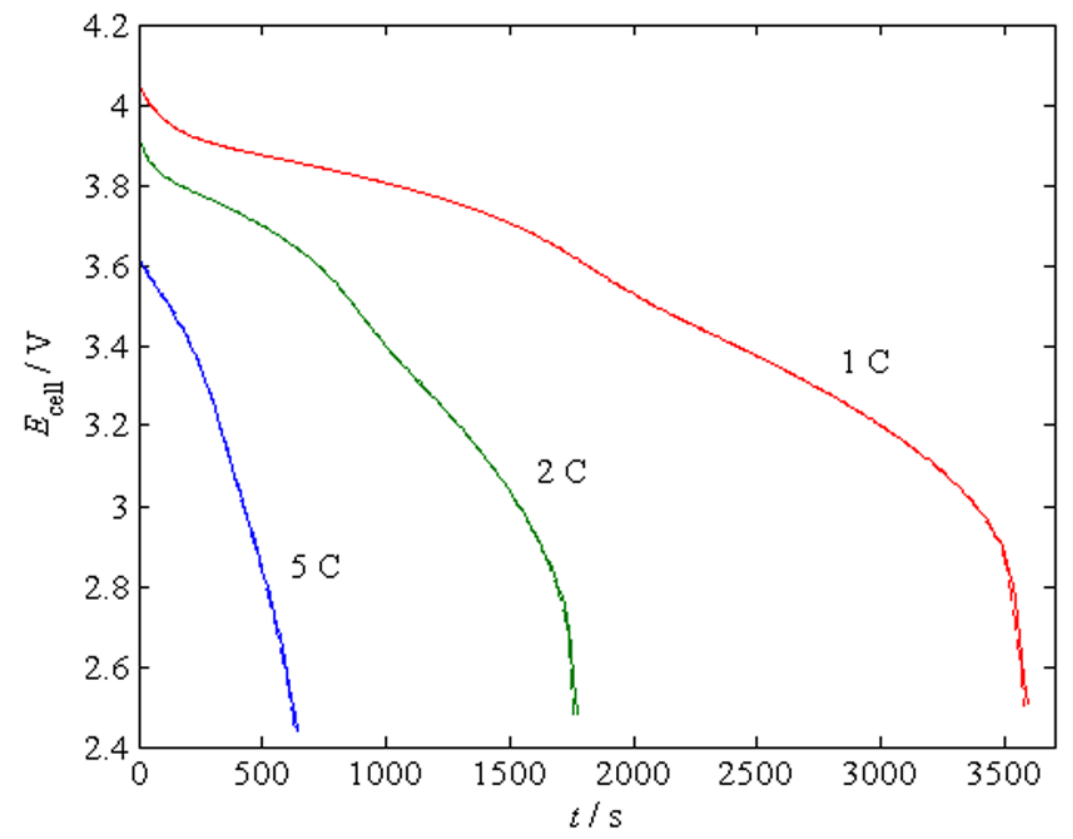

Figure 2. Battery voltage during discharge at various discharge rates for square (continuous) and circular (dashed) electrodes

Because electrodes in a 3D array are arranged in a parallel configuration, an array containing a large number of electrodes will have a greater capacity compared to a single pair of electrodes as compared to the 2D cell. Having more electrodes in an array would increase the total current delivered but keeping the potential unchanged. The array capacity can also be increased by elongating the electrodes into the plane, instead of increasing the capacity by making the electrodes thicker as in 2D batteries. As such, power density is not sacrificed for an increase in the array capacity in 3D batteries since the distance between electrodes remains the same. On the other hand, array capacity is gained at the expense of power density in 2D cells as an increase in capacity is attained by increasing the thickness of electrodes.

\section{Electrochemical behaviour}

During discharge, lithium ions deintercalate from the active material in the negative electrode and enter the electrolyte; the reverse process happens in the positive electrode. Hence, the concentration of lithium ions in the electrolyte increases in the negative electrode and decreases in the positive electrode, as depicted in Fig. 3. The time constant for diffusion is around $100 \mathrm{~s}$ $\left(w_{i}^{2} / D_{1}^{\text {eff }}\right)$ after which the concentration profile reaches a pseudo-steady state. The lithium-ion concentration reaches a maximum of $2100 \mathrm{~mol} \mathrm{~m}^{-3}$ at $1 \mathrm{C}$-rate and $2500 \mathrm{~mol} \mathrm{~m}^{-3}$ at $5 \mathrm{C}$-rate in the cell, as well as a minimum of $1900 \mathrm{~mol} \mathrm{~m}^{-3}$ at $1 \mathrm{C}$-rate and $1700 \mathrm{~mol} \mathrm{~m}^{-3}$ at 5 C-rate. These maximum and minimum concentration values are found in the negative and positive corner electrodes respectively, since the corner electrodes are only surrounded by two nearest neighbours: a negative corner electrode has fewer adjacent positive electrodes to consume fewer 
lithium ions, while a positive corner electrode has fewer adjacent negative electrodes to produce lithium ions.

(a)

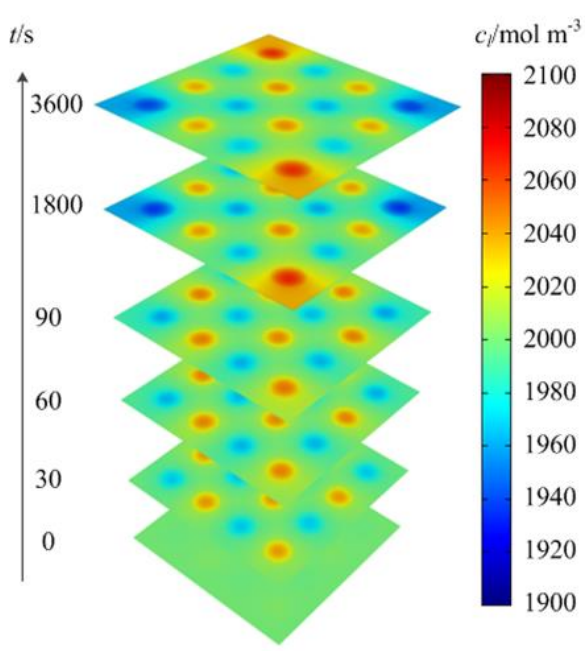

(b)

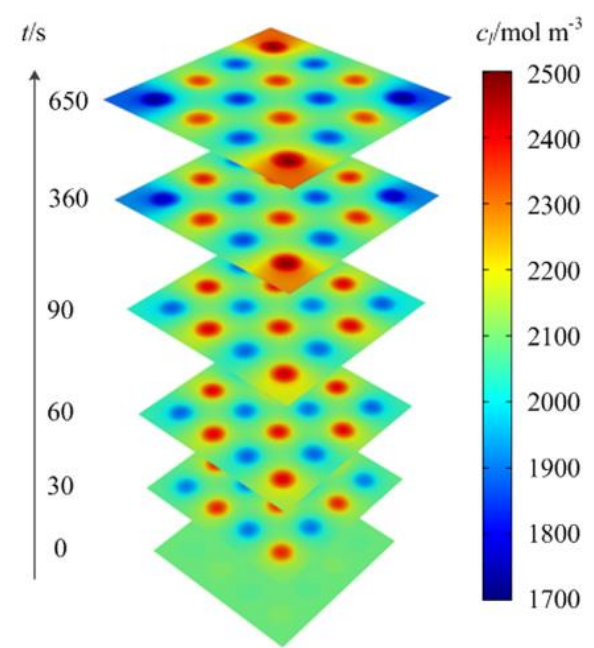

Figure 3. Variation of concentration of lithium ions in the electrolyte along the xz-plane at $y=2.8 \times 10^{-4} \mathrm{~m}$ at various times during discharge at $1 \mathrm{C}$ and $5 \mathrm{C}$-rates for the circular electrodes

Moreover, there is variation in the lithium ion concentration in the electrolyte along the height of the electrodes, as illustrated in Fig. 4a. Both arrays display similar behaviour, with the square electrode array attaining a slightly higher concentration of $2105 \mathrm{~mol} \mathrm{~m}^{-3}$ in a negative corner electrode compared to $2090 \mathrm{~mol} \mathrm{~m}^{-3}$ in the equivalent circular electrode. Extreme values are observed in the areas nearer the current collector: negative electrodes have the highest lithium ion concentrations near the negative current collector as consumption of lithium ions by the positive electrode is lowest near the negative current collector; positive electrodes have the lowest lithium ion concentrations near the positive current collector as production of lithium ions in the negative electrode is lowest near the positive current collector.

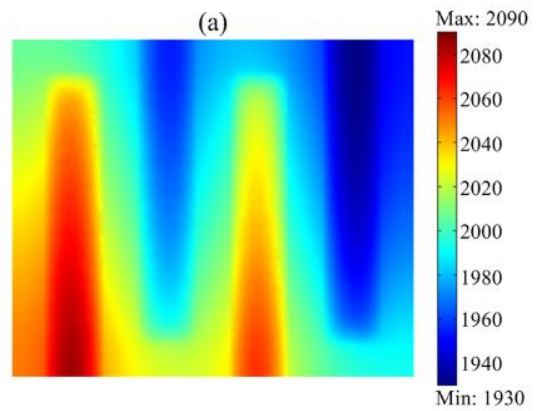

(c)

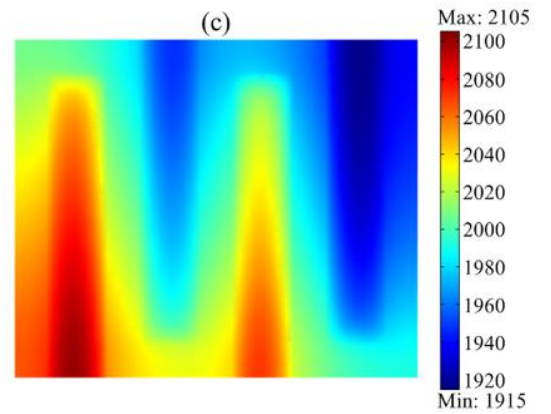

(b)

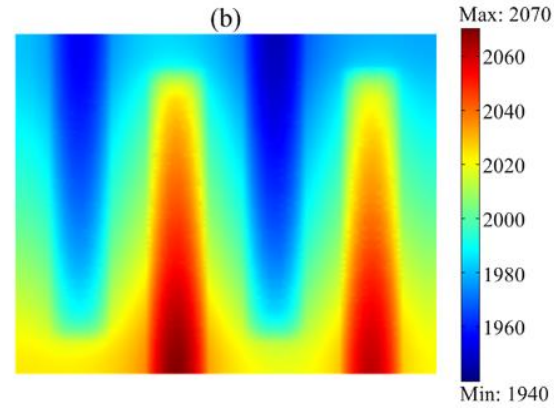

(d)

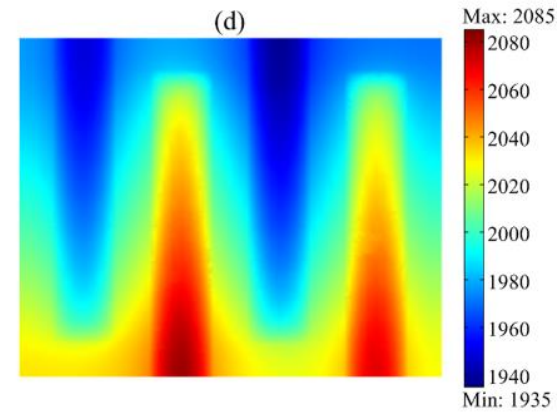

Figure 4a. Concentration profile of lithium ions in the electrolyte at the end of discharge at $1 \mathrm{C}$-rate along the $x y$-plane at $z=10^{-4} \mathrm{~m}(a, c)$ and at $z=2.5 \times 10^{-4} \mathrm{~m}(b, d)$ for circular and square electrodes respectively 
(a)

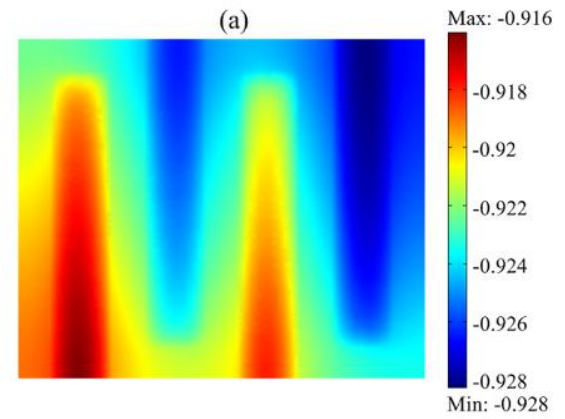

(c)

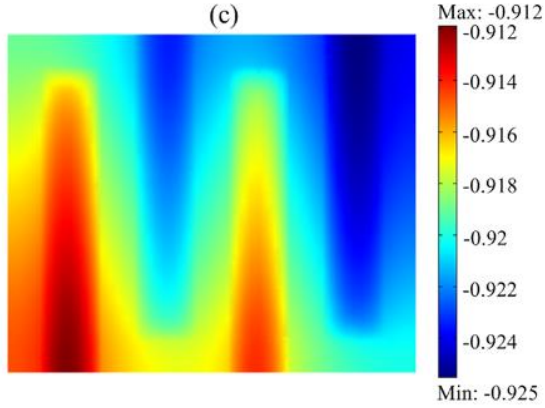

(b)

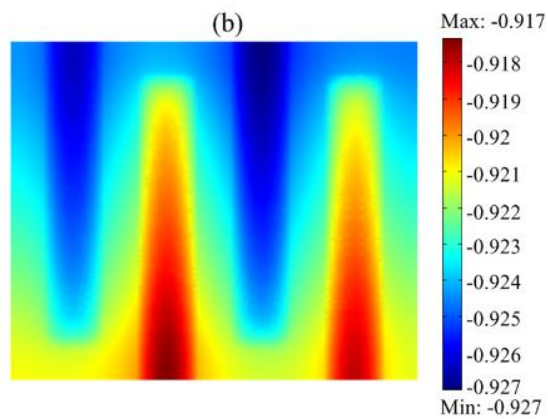

(d)

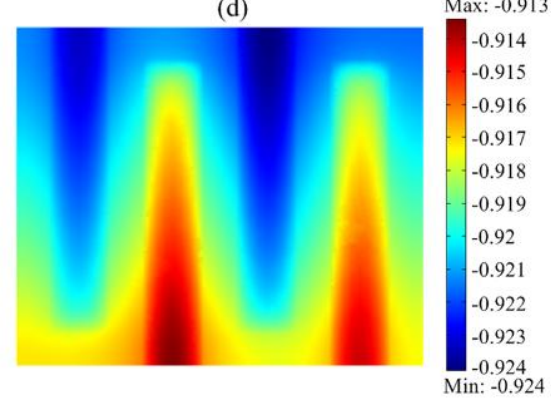

Figure $4 b$. Liquid phase potential profile in the electrolyte at the end of discharge at $1 \mathrm{C}$-rate along the $x y$ plane at $z=10^{-4} \mathrm{~m}(a, c)$ and at $z=2.5 \times 10^{-4} \mathrm{~m}(b, d)$ for circular and square electrodes respectively

The unequal distribution of lithium ions also results in a variation in the liquid phase potential in the cell, as can be seen in Fig. 4b. Again, behaviour of both arrays are similar, with a maximum potential drop of $12 \times 10^{-3} \mathrm{~V}$ in the circular electrode array compared to $13 \times 10^{-3} \mathrm{~V}$ in the square electrode array. This potential drop, which can be attributed to ohmic losses and the concentration overpotential, gradually accentuates as the concentration gradient steepens during discharge. Extreme values of potential drop are observed nearest to the current collectors, because of similar reasons that cause extreme values in lithium ion concentration. First, we shall explore the global behaviour of the 3D battery in terms of potential during discharge for discharge curves.

\section{Heat generation and thermal behaviour}

The temperature of both circular and square arrays increases over time during discharge due to heat generation, as shown in Fig. 5 . For the square electrode array, the temperature increases by $12 \mathrm{~K}, 20 \mathrm{~K}$ and $30 \mathrm{~K}$ above the ambient temperature for discharge rates of $1 \mathrm{C}, 2 \mathrm{C}$ and $5 \mathrm{C}$, respectively.

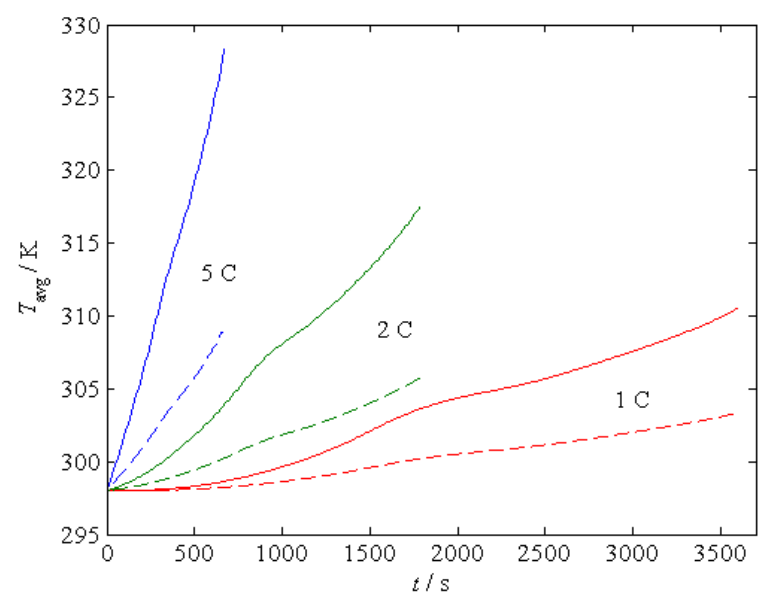

Figure 5. Average battery temperature of the battery during discharge at various discharge rates for square (continuous) and circular (dashed) electrodes 
On the other hand, for the circular electrode array, the temperature increase is smaller, being $5 \mathrm{~K}, 8 \mathrm{~K}$ and $11 \mathrm{~K}$ for same discharge rates. Such a difference in array temperature over time is due to the higher volume of the square electrodes as compared to the circular ones leading to more heat generation in the square electrodes than the circular ones.

A comparison of the contribution from various layers towards heat generation is provided in Figs. 6a-b. The negative electrode is the highest contributor, amounting to $60 \%$ in both discharge rates, due to its lower ionic conductivity and less porous nature. The positive electrode is the second highest contributor. Heat generation in the current collector and electrolyte is purely by ohmic heating and remains almost constant throughout the discharge.

a

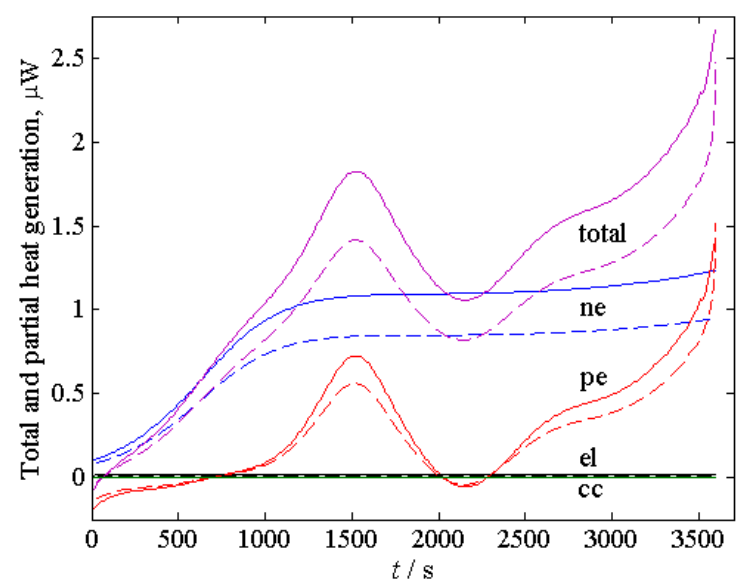

b

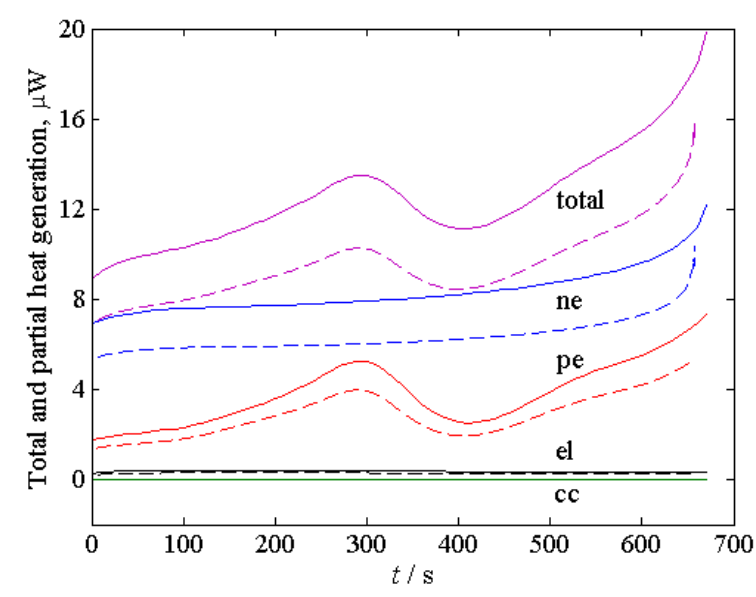

Figure 6. Time history of total heat generation and heat generation in various layers during discharge for square (continuous) and circular (dashed) electrodes at $\boldsymbol{a}-1 \mathrm{C}$-rate, and $\boldsymbol{b}-5 \mathrm{C}$-rate

\section{Reliability Analysis}

Due to the similarity in the behaviour of both the circular and square electrode arrays in the reliability analysis, we will only consider the circular electrode array. The behaviour of neighbouring electrodes is studied when either a target anode or a cathode malfunctions/fails. Given the extreme discharge conditions of $5 \mathrm{C}$ discharge for lithium-ion batteries, we shall discuss the results for $5 \mathrm{C}$ discharge rates as a worst-case scenario.

\section{Discharge curves}

The variation of cell voltage with time during discharge at $5 \mathrm{C}$-rate under both perturbed cases is presented in Fig. 7. As expected, there is a decrease in the discharge time compared to the normal case due to the loss in the energy capacity of the battery because of the malfunctioning of the electrodes. When the positive electrode malfunctions, there is a decrease of $60 \mathrm{~s}$ in the discharge time corresponding to a $10 \%$ decrease in the energy capacity. Similarly, for the malfunctioning negative electrode, there is a decrease of $110 \mathrm{~s}$ in the discharge time corresponding to a $17 \%$ decrease in the energy capacity. The negative electrode has higher theoretical capacity than the positive electrode (defined as $C_{i}$ in the constitutive relations) and hence the capacity of the battery is reduced more when the negative electrode malfunctions compared to the positive electrode malfunctioning. Thus, unlike the conventional parallel-plate design, the 3D array is still able to safely generate power when an electrode malfunctions, though with a lower energy capacity. 


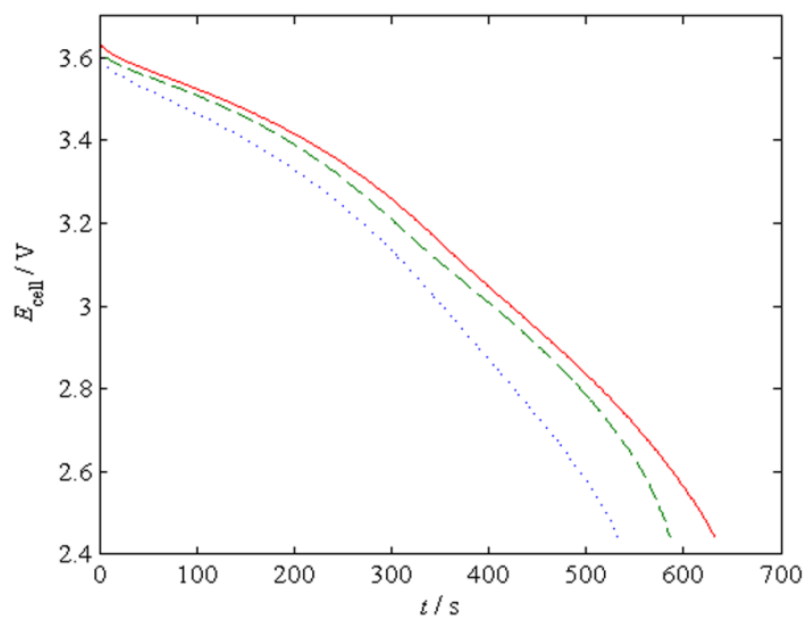

Figure 7. Battery voltage during discharge at 5 C-rate under normal (continuous) and perturbed cases of malfunctioning either positive (dashed) or negative (dotted) electrodes as marked in Fig. 1

\section{Electrochemical behaviour}

When a positive electrode malfunctions, the concentration distribution of lithium ions in the rest of the array away from the perturbed cell remains largely similar throughout high discharge rates relative to that in a non-perturbed array, as shown by comparing Figs. $3 \mathrm{~b}$ and $8 \mathrm{a}$. However, the concentration of lithium ions in the electrolyte in the malfunctioning positive electrode increases continuously from the initial value of $2 \times 10^{3} \mathrm{~mol} \mathrm{~m}^{-3}$ to $2.3 \times 10^{3} \mathrm{~mol} \mathrm{~m}^{-3}$ at the end of discharge, compared to a decrease to $1.8 \times 10^{3} \mathrm{~mol} \mathrm{~m}^{-3}$ on average in the electrolyte in the other positive electrodes. Because there is an inflow of ions from the adjacent negative electrodes that act as source of lithium ions, but no reaction in the active material taking place to consume them, lithium ions accumulate within the electrolyte in the malfunctioning positive electrode. This effect is concentrated locally in and around the malfunctioning electrode as shown in Fig. 8a and is insignificant towards the other electrodes in the array.

(a)

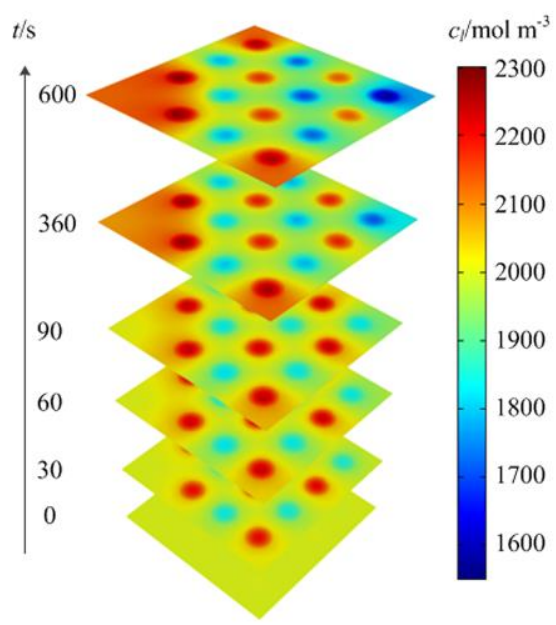

(b)

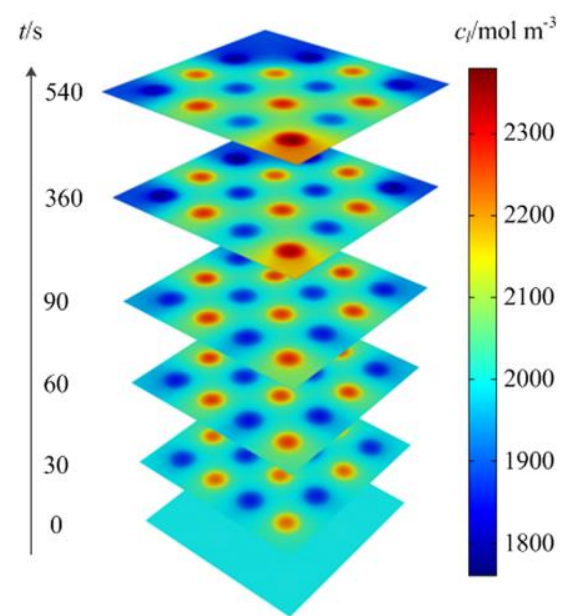

Figure 8. Variation of concentration of lithium ions in the electrolyte along the $x z$-plane at $y=2.8 \times 10^{-4} \mathrm{~m}$ at various times during discharge at $5 \mathrm{C}$-rate under malfunctioning (a) positive and (b) negative electrodes of circular cross-section

When a negative electrode malfunctions, the concentration distribution of lithium ions in the rest of the array also remains largely similar throughout high discharge rates relative to that in a non-perturbed array, as shown by comparing Figs. $3 \mathrm{~b}$ and $8 \mathrm{~b}$. However, the concentration of 
lithium ions in the electrolyte in the malfunctioning negative electrode decreases continuously from the initial value of $2 \times 10^{3} \mathrm{~mol} \mathrm{~m}^{-3}$ to $1.8 \times 10^{3} \mathrm{~mol} \mathrm{~m}^{-3}$ at the end of discharge, compared to an increase to $2.3 \times 10^{3} \mathrm{~mol} \mathrm{~m}^{-3}$ on average in the other negative electrodes. As the adjacent positive electrodes act as sink for lithium ions due to the reduction reaction, a concentration gradient develops between these electrodes and the malfunctioning electrode. Lithium ions diffuse into the positive electrodes from the electrolyte and the malfunctioning negative electrode does not give out the lithium ions due to the absence of reaction in the active material, resulting in the depletion of the ions within the electrolyte there. This effect is also concentrated locally in and around the malfunctioning electrode as shown in Fig. $8 \mathrm{~b}$ and is insignificant towards the rest of the array.

The cessation of function of any electrode would directly impact the electrochemical behaviour on neighbouring electrodes to a significant degree, due to diffusion of lithium ions in and out of the malfunctioning electrode which otherwise would not occur in a non-perturbed array. However, this effect is negligible for electrodes further away during both the reaction phase and the diffusion phase, due to the presence of many other functioning electrodes in an otherwise intact array.

\section{Heat generation and thermal behaviour}

The rise in average temperature of the array in the perturbed cases in similar to that in the standard discharge, in that the average temperature increases steadily at first before becoming more gradual towards the end of discharge. However, there are some minor differences. When a positive electrode malfunctions, the increase in temperature is smaller by $0-2 \mathrm{~K}$ compared to the normal case during a $5 \mathrm{C}$ discharge, and only $0-0.2 \mathrm{~K}$ during $1 \mathrm{C}$ discharge rates, due to the decrease in the number of heat sources. On the other hand, when an anode malfunctions, the increase in temperature is smaller by $0-1 \mathrm{~K}$ compared to the normal case during a $5 \mathrm{C}$ discharge, and $0-0.2 \mathrm{~K}$ during $1 \mathrm{C}$ discharge, due to the decreased heat generation in the negative electrodes which is highest contributor to heat generation as seen before. Differences in thermal behavior are negligible for electrodes further away from the malfunctioning electrode.

\section{Conclusions}

This paper presents a thermal-electrochemical coupled model for next-generation 3D Li-ion batteries applied to two different electrode geometries - square and circular. A reliability analysis was also conducted to analyse the effect of a single malfunctioning electrode on the rest of the array.

In summary, the performance of the 3D cell during discharge under normal conditions was similar for both the square and circular electrode arrays; potential, thermal behaviour and electrochemical behaviour also did not show marked differences at any discharge rates under the selected design parameters. Furthermore, the cell capacity can be increased by simply adding more electrodes in the plane of the array or increasing the height of the electrodes, without compromising on power density unlike in the conventional 2D design.

The performance of the 3D electrode array during perturbed conditions, in terms of the changes in the potential and the concentration distribution, was only significant in and around the malfunctioning electrode. A maximum change of around $17 \%$ in the energy capacity and $10 \%$ in lithium ion concentration in the electrolyte in and around the malfunctioning electrode under a 5 $\mathrm{C}$ discharge was seen. Deviation in electrochemical behaviour is negligible more than one cell away from the malfunctioning electrode. The model can also easily be extended to account for various types of 3D designs and conditions. 
This design demonstrates a clear advantage in terms of reliability over the 2D battery, as the 3D array does not stop functioning even if one of the electrodes fail, unlike the conventional 2D parallel-plate design. This allows power to be continuously delivered in a safe manner until the battery is eventually replaced, as there is only minor deviation in thermal behaviour of the cell. As the array behaviour is likely to be significantly affected only when many electrodes malfunction, actual implementation of 3D batteries with full-size arrays is viable. With good performance due to the redundancy provided by the array, the 3D cell will be able to deliver reliability benefits which are crucial in many modern applications. Further, the model can be extended to study the transport in solid polymer electrolytes as well. Also, the model can be employed to study the behaviour of the battery when there is short-circuiting of the electrodes which seems to be a common problem in microbatteries.

\section{Nomenclature}

\begin{tabular}{|c|c|c|c|}
\hline$A_{\mathrm{s}}$ & $\begin{array}{l}\text { specific surface area for the faradaic reaction per unit } \\
\text { volume, } \mathrm{m}^{2} / \mathrm{m}^{3}\end{array}$ & $C_{\mathrm{s}}$ & $\begin{array}{l}\text { concentration of lithium in active material in the } \\
\text { electrodes, } \mathrm{mol} \mathrm{m}^{-3}\end{array}$ \\
\hline$C_{1}$ & electrolyte concentration, $\mathrm{mol} \mathrm{m}^{-3}$ & $C_{\mathrm{p}}$ & specific heat capacity, $\mathrm{J} \mathrm{kg}^{-1} \mathrm{~K}^{-1}$ \\
\hline$C_{\mathrm{s}}^{\mathrm{avg}}$ & average concentration of $\mathrm{Li}$ in the active material, $\mathrm{mol} \mathrm{m}^{-3}$ & $c_{\mathrm{s}}^{\text {surf }}$ & surface concentration of $\mathrm{Li}$ in the active material, $\mathrm{mol} \mathrm{m}^{-3}$ \\
\hline$D_{1}$ & diffusion coefficient of electrolyte, $\mathrm{m}^{2} \mathrm{~s}^{-1}$ & $D_{\mathrm{s}}$ & $\begin{array}{l}\text { diffusion coefficient of } \mathrm{Li} \text { in the active material in the } \\
\text { electrodes, } \mathrm{m}^{2} \mathrm{~s}^{-1}\end{array}$ \\
\hline$E_{\mathrm{a}}$ & activation energy for a variable, $\mathrm{kJ} \mathrm{mol}^{-1}$ & $F$ & Faraday's constant, $96487 \mathrm{C} \mathrm{mol}^{-1}$ \\
\hline$H$ & height of the battery, $\mathrm{m}$ & $h_{\mathrm{i}}$ & height of the functional layers in the battery, $\mathrm{m}$ \\
\hline$h_{\mathrm{t}}$ & heat transfer coefficient, $\mathrm{W} \mathrm{m}^{-2} \mathrm{~K}^{-1}$ & $i_{\text {app }}$ & applied current density, $\mathrm{A} \mathrm{m}^{-2}$ \\
\hline$i_{0}$ & exchange current density, $\mathrm{A} \mathrm{m}^{-2}$ & $i_{1}$ & liquid phase current density, $\mathrm{A} \mathrm{m}^{-2}$ \\
\hline$i_{\mathrm{s}}$ & solid phase current density, $\mathrm{A} \mathrm{m}^{-2}$ & $i_{\mathrm{f}}$ & faradaic transfer current density, $\mathrm{A} \mathrm{m}^{-2}$ \\
\hline$J$ & local charge transfer current per unit volume, $\mathrm{A} \mathrm{m}^{-3}$ & $k$ & thermal conductivity, $\mathrm{W} \mathrm{m}^{-1} \mathrm{~K}^{-1}$ \\
\hline$k_{0}$ & reaction rate constant, $\mathrm{mol}^{2.5} \mathrm{~m}^{-0.5} \mathrm{~s}^{-1}$ & $L$ & length of the battery, $\mathrm{m}$ \\
\hline$I_{\mathrm{s}}$ & diffusion length, $\mathrm{m}$ & $N_{1}$ & species (lithium ion) flux, $\mathrm{mol} \mathrm{m}^{-2} \mathrm{~s}^{-1}$ \\
\hline $\mathrm{n}$ & normal vector & $Q$ & volumetric heat generation, $\mathrm{W} \mathrm{m}^{-3}$ \\
\hline$q$ & conductive heat flux, $\mathrm{W} \mathrm{m}^{-2}$ & $R$ & gas constant, $\mathrm{J} \mathrm{mol}^{-1} \mathrm{~K}^{-1}$ \\
\hline$R_{\mathrm{s}}$ & radius of active material, $\mathrm{m}$ & $r$ & radial coordinate \\
\hline$t$ & time, $s$ & $t_{+}^{0}$ & transference number of cation \\
\hline$T$ & temperature, $\mathrm{K}$ & $T_{\mathrm{a}}, T_{0}$ & ambient and initial temperature, $\mathrm{K}$ \\
\hline$T_{\text {ref }}$ & reference temperature, $298.15 \mathrm{~K}$ & $U_{\text {ref }}$ & open circuit potential of the electrode, $\mathrm{V}$ \\
\hline$V_{i}$ & volume of the electrode $\mathrm{i}, \mathrm{m}^{3}$ & $W$ & width of the battery, $\mathrm{m}$ \\
\hline$W_{\mathrm{i}}$ & thickness of the layer $\mathrm{i}, \mathrm{m}$ & & \\
\hline
\end{tabular}

\section{Greek}

\begin{tabular}{|c|c|}
\hline$\alpha_{\mathrm{a}}, \alpha_{\mathrm{c}}$ anodic/cathodic transfer coefficient & $\varepsilon_{\mathrm{l}} \quad$ volume fraction of the electrolyte in the electrodes \\
\hline$\varepsilon_{\mathrm{f}} \begin{array}{l}\text { volume fraction of the conductive filler additive in the } \\
\text { electrodes }\end{array}$ & $\varepsilon_{\mathrm{p}} \quad$ volume fraction of the polymer in the electrodes \\
\hline$\eta \quad$ overpotential, $\mathrm{V}$ & $\gamma \quad$ Bruggeman constant (=1.5) \\
\hline$\rho$ density, $\mathrm{kg} \mathrm{m}^{-3}$ & $\sigma_{\mathrm{I}} \quad$ ionic conductivity of electrolyte, $\mathrm{S} \mathrm{m}^{-1}$ \\
\hline$\sigma_{\mathrm{s}}$ electronic conductivity of solid matrix, $\mathrm{S} \mathrm{m}^{-1}$ & $\varphi_{\mathrm{I}} \quad$ liquid phase potential, $\mathrm{V}$ \\
\hline$\varphi_{\mathrm{s}}$ solid phase potential, $\mathrm{V}$ & $\mathrm{v} \quad$ local state of charge of the electrodes \\
\hline
\end{tabular}

\section{Subscripts}

\begin{tabular}{|c|c|}
\hline cc current collector & ne negative electrode \\
\hline pe positive electrode & el electrolyte \\
\hline I liquid/ electrolyte & \\
\cline { 1 - 2 } &
\end{tabular}

\section{Superscripts}

\begin{tabular}{|c|c|}
\hline $0 \quad$ initial values & eff effective values \\
\hline max maximum values & \multicolumn{2}{|l}{} \\
\hline
\end{tabular}




\section{References}

[1] J. W. Long, B. Dunn, D. R. Rolison, H. S. White, Chem. Rev. 104 (2004) 4463-4492

[2] M. Beidaghi, C. Wang, Micro- and Nanotechnology Sensors, Systems, and Applications II. Edited by George, Thomas; Saif Islam, M.; Dutta, Achyut K. Proceedings of the SPIE, Volume 7679, 2010

[3] M. Roberts, P. Johns, J. Owen, D. Brandell, K. Edstrom, G. E. Enany, C. Guery, D. Golodnitsky, M. Lacey, C. Lecoeur, H. Mazor, E. Peled, E. Perre, M. M. Shaijumon, P. Simon, P.-L. Taberna, J. Mater. Chem. 21 (2011) 9876-9890

[4] J. Weinert, A. Burke, X. Wei, J. Power Sources 172 (2) (2007) 938-945

[5] J. Tarascon, M. Armand, Nature 414 (2001) 359-367

[6] R. W. Hart, H. S. White, B. Dunn, D. R. Rolison, Electrochem. Commun. 5 (2003) 120-123

[7] B. Dunn, J. W. Long, D. R. Rolison, The Electrochem. Soc. Interface 17(3) (2008) 49-53

[8] R. Salot, S. Martin, S. Oukassi, M. Bedjaoui, J. Ubrig, Appl. Surf. Sci. 256(3) (2009) S54-S57

[9] H.-S. Min, B. Y. Park, L. Taherabadi, C. Wang, Y. Yeh, R. Zaouk, M. J. Madou, B. Dunn, J. Power Sources 178 (2008) 795-800

[10] J. F. M. Oudenhoven, L. Baggetto, P. H. L. Notten, Adv. Energy Mater. 1(1) (2011) 10-33

[11] J. Kim, X. Song, K. Kinoshita, M. Madou, R. White, J. Electrochem. Soc. 145(7) (1998) 23142319

[12] R. Kostecki, X. Song, K. Kinoshita, J. Electrochem. Soc. 147(5) (2000) 1878-1881.

[13] S. Ranganathan, R. McCreery, S. M. Majji, M. Madou, J. Electrochem. Soc. 147(1) (2000) 277-282

[14] C. Wang, L. Taherabadi, G. Jia, Y.Yeh, B. Dunn, M. Madou, Electrochem. Solid-State Lett. 7(11) (2004) A435-A438

[15] D. R. Rolison, J. W. Long, J. C. Lytle, A. E. Fischer, M. E. B. Christopher P. Rhodes and, Todd M. McEvoy, A. M. Lubers, Chem. Soc. Rev. 38(1) (2009) 226-252

[16] Y. Shao-Horn, C. Hidrovo, S. Jurga, H. Smith, G. Barbastathis, $204^{\text {th }}$ meeting of the Electrochemical Society, Pennington, NJ, abstr. 1279, 2003

[17] K. Dokko, J. Sugaya, H. Nakano, T. Yasukawa, T. Matsue, K. Kanamura, Electrochem. Commun. 9 (2007) 857-862

[18] G. T. Teixidor, R. B. Zaouk, B. Y. Park, M. J. Madou, J. Power Sources 183 (2008) 730-740

[19] H.-S. Min, B. Y. Park, L. Taherabadi, C. Wang, Y. Yeh, R. Zaouk, M. J. Madou, B. Dunn, J. Power Sources 178(2) (2008) 795-800

[20] M. Fleischauer, J. Li, M. Brett, J. Electrochem. Soc. 156(1) (2009) A33-A36

[21] M. Kotobuki, Y. Suzuki, H. Munakata, K. Kanamura, Y. Sato, K. Yamamoto, T. Yoshida, J. Electrochem. Soc. 157(4) (2010) A493-A498

[22] K. Sun, T.-S. Wei, B. Y. Ahn, J. Y. Seo, S. J. Dillon, J. A. Lewis, Adv. Mater. 5 (2013) 1-5

[23] V. Zadin, H. Kasemagi, A. Aabloo, D. Brandell, J. Power Sources 195 (2010) 6218-6224

[24] V. Zadin, D. Brandell, H. Kasemgi, A. Aabloo, J. O. Thomas, Solid State Ionics 192 (2011), 279-283

[25] V. Zadin, D. Brandell, Electrochim. Acta 57 (2011) 237-243

[26] T. Fuller, M. Doyle, J. Newman, J. Electrochem. Soc. 141(1) (1994) 1-10

[27] M. Doyle, J. Newman, J. Electrochem. Soc. 143(6) (1996) 1890-1903

[28] P. M. Gomadam, J. W. Weidner, R. A. Dougal, R. E. White, J. Power Sources 110 (2002) 267284

[29] C.-W. Wang, A. M. Sastry, J. Electrochem. Soc. 154(11) (2007) A1035-A1047

[30] X. Zhang, Electrochim. Acta 56 (2011) 1246-1255

[31] K. Somasundaram, E. Birgersson, A. S. Mujumdar, J. Power Sources 203 (2012) 84-96

[32] J. Newman, W. Tiedemann, AIChE J. 21(1) (1975) 25-41 
[33] J. Newman, K. E. T. Alyea (Eds.), Electrochemical Systems, 3rd Edition, John Wiley and Sons, Inc., 2004

[34] V. Srinivasan, C. Y. Wang, J. Electrochem. Soc. 150(1) (2003) A98-A106

[35] Comsol Multiphysics 3.5a, http://www.comsol.com, visited May 11, 2009

[36] B. A. Johnson, R. E. White, J. Power Sources 70 (1998) 48-54

[37] D. R. Baker, M. W. Verbrugge, J. Electrochem. Soc. 146(7) (1999) 2413-2424 


\section{Appendix A}

Table A.1 Governing equations

\begin{tabular}{|l|l|}
\hline \multicolumn{1}{|c|}{ Governing equation } & \multicolumn{1}{c|}{ Flux } \\
\hline$\nabla \cdot \mathbf{i}_{s}=-J$ (pe, ne, cc) & $\mathbf{i}_{s}=-\sigma_{s}^{\text {eff }} \nabla \varphi_{s}$ \\
\hline$\nabla \cdot \mathbf{i}_{l}=J(\mathrm{pe}, \mathrm{ne}, \mathrm{el})$ & $\mathbf{i}_{l}=-\sigma_{l}^{\text {eff }} \nabla \varphi_{l}+\frac{2 R T \sigma_{l}^{\text {eff }}}{F}\left(1-t_{+}^{0}\right) \nabla\left(\ln c_{l}\right)$ \\
\hline$\varepsilon_{l} \frac{\partial c_{l}}{\partial t}+\nabla \cdot \mathbf{N}_{l}=\frac{J}{F}(\mathrm{pe}, \mathrm{ne}, \mathrm{el})$ & $\mathbf{N}_{l}=-D_{l}^{\text {eff }} \nabla c_{l}+\frac{\mathbf{i}_{l} t_{+}^{0}}{F}$ \\
\hline$\frac{D_{s}}{l_{s}}\left(c_{s}^{\text {surf }}-c_{s}^{\text {avg }}\right)=-\frac{i_{f}}{F}, \frac{d c_{s}^{\text {avg }}}{d t}=-\frac{3 i_{f}}{F R_{s}},(\mathrm{ne}, \mathrm{pe})$ & - \\
\hline$\left(\rho C_{p}\right)^{\text {eff }} \frac{\partial T}{\partial t}+\nabla \cdot \mathbf{q}=Q(\mathrm{pe}, \mathrm{ne}, \mathrm{el}, \mathrm{cc})$ & $\mathbf{q}=-k^{\text {eff }} \nabla T$ \\
\hline
\end{tabular}

\section{Appendix B}

Table B.1 Constitutive relations

\begin{tabular}{|c|c|}
\hline$J=$ & $\begin{cases}A_{s} i_{f} & \text { (ne, pe) } \\
0 & (\mathrm{el}, \mathrm{cc})\end{cases}$ \\
\hline$i_{f}=$ & $i_{0}\left\{\exp \left(\frac{\alpha_{a} \eta F}{R T}\right)-\exp \left(-\frac{\alpha_{c} \eta F}{R T}\right)\right\}$ \\
\hline$i_{0}=$ & $F k_{o} \sqrt{c_{l}\left(c_{s}^{\max }-c_{s}^{\text {surf }}\right) c_{s}^{\text {surf }}}$ \\
\hline$\eta=$ & $\varphi_{s}-\varphi_{l}-U_{r e f, \mathrm{i}}^{\text {eff }}, \mathrm{i}=\mathrm{ne}, \mathrm{pe}$ \\
\hline$A_{s}=$ & $\frac{3\left(1-\varepsilon_{1}-\varepsilon_{f}-\varepsilon_{p}\right)}{R_{s}}$ \\
\hline$Q=$ & $J \eta+J T \frac{\partial U_{r e f, i}}{\partial T}+\sigma_{s}^{e f f}\left(\nabla \varphi_{s}\right)^{2}+\sigma_{l}^{e f f}\left(\nabla \varphi_{l}\right)^{2}+\frac{2 R T \sigma_{l}^{e f f}}{F}\left(1-t_{+}^{0}\right) \nabla\left(\ln c_{l}\right) \cdot \nabla \varphi_{l}, \mathrm{i}=$ ne, pe \\
\hline$\vartheta_{\mathrm{ne}}, \vartheta_{\mathrm{pe}}=$ & $\frac{c_{s}^{\text {surf }}}{c_{s}^{\max }}$ \\
\hline$C_{\mathrm{i}}=$ & $V_{\mathrm{i}}\left(1-\varepsilon_{l}-\varepsilon_{f}-\varepsilon_{p}\right) \rho_{\mathrm{i}} C_{t h}, \mathrm{i}=$ ne, pe \\
\hline$U_{r e f, i}^{e f f}=$ & $U_{r e f, i}+\left(T-T_{r e f}\right) \frac{\partial U_{r e f, i}}{\partial T}, i=$ ne, pe \\
\hline$\sigma_{s}^{e f f}=$ & $\sigma_{s}\left(1-\varepsilon_{1}-\varepsilon_{f}-\varepsilon_{p}\right)$ \\
\hline$\sigma_{1}^{e f f}=$ & $\sigma, \varepsilon_{l}^{\gamma}$ \\
\hline$k_{\mathrm{i}}^{e f f}=$ & $k_{\mathrm{i}}\left(1-\varepsilon_{l}\right)+k_{l} \varepsilon_{l}, \mathrm{i}=\mathrm{ne}, \mathrm{pe}$ \\
\hline$\left(\rho C_{p}\right)_{i}^{e f f}=$ & $\left(\rho C_{p}\right)_{i}\left(1-\varepsilon_{l}\right)+\left(\rho C_{p}\right), \varepsilon_{l}, \mathrm{i}=$ ne, pe \\
\hline$D_{l}^{\text {eff }}=$ & $D, \varepsilon_{1}^{\gamma}$ \\
\hline$\sigma_{1}=$ & $-1.172 \times 10^{-14} c_{l}^{4}+1.3605 \times 10^{-10} c_{l}^{3}-5.2245 \times 10^{-7} c_{l}^{2}+6.7461 \times 10^{-4} c_{l}+1.0793 \times 10^{-2}$ \\
\hline$\Theta(T)=$ & $\Theta\left(T_{\text {ref }}\right) \exp \left[\frac{E_{a, \Theta}}{R}\left(\frac{1}{T_{r e f}}-\frac{1}{T}\right)\right], \Theta=D_{s}, D_{l}, \sigma_{l}$ \\
\hline
\end{tabular}




\begin{tabular}{|r|l|}
\hline$I_{s}=$ & $\frac{R_{s}}{5}$ \\
\hline$\varphi_{s}^{0}=$ & $U_{\text {ref, pe }}\left(\vartheta_{\mathrm{pe}}^{0}\right)-U_{\text {ref, ne }}\left(\vartheta_{\mathrm{ne}}^{0}\right)$ \\
\hline$\varphi_{l}^{0}=$ & $-U_{\text {ref, ne }}\left(\vartheta_{\mathrm{ne}}^{0}\right)$ \\
\hline$E_{\text {cell }}=$ & $\left.\varphi_{s}\right|_{1}-\left.\varphi_{s}\right|_{\mathrm{VII}}$ \\
\hline$\frac{\partial U_{\text {ref, ne }}}{\partial T}=$ & $\frac{344.1347 \mathrm{exp}\left(-32.9633 \vartheta_{\mathrm{ne}}+8.3167\right)}{1+749.0756 \mathrm{exp}\left(-34.7909 \vartheta_{\mathrm{ne}}+8.8871\right)}-0.852 \vartheta_{\mathrm{ne}}+0.3622 \vartheta_{\mathrm{ne}}^{2}+0.2698$ \\
\hline$\frac{\partial U_{\text {ref, pe }}}{\partial T}=$ & $\begin{array}{c}-4.1453+8.1471 \vartheta_{\mathrm{pe}}-26.0645 \vartheta_{\mathrm{pe}}^{2}+12.766 \vartheta_{\mathrm{pe}}^{3}+4.3127 \exp \left(0.5715 \vartheta_{\mathrm{pe}}\right)-0.1842 \exp \left(-\frac{\vartheta_{\mathrm{pe}}-0.5169}{0.0462}\right)^{2} \\
+1.2816 \sin \left(-4.9916 \vartheta_{\mathrm{pe}}\right)-0.0904 \sin \left(-20.9669 \vartheta_{\mathrm{pe}}-12.5788\right)+0.0313 \sin \left(31.7663 \vartheta_{\mathrm{pe}}-22.4295\right)\end{array}$ \\
\hline$U_{\text {ref, ne }}=$ & $-0.16+1.32 \exp \left(-3 \vartheta_{\mathrm{ne}}\right)+10 \exp \left(-2000 \vartheta_{\mathrm{ne}}\right)$ \\
\hline$U_{\text {ref, pe }}=$ & $\begin{array}{c}4.1983+0.0565 \tanh \left(-14.5546 \vartheta_{\mathrm{pe}}+8.6094\right)-0.0275\left(\frac{1}{\left(0.9984-\vartheta_{\mathrm{pe}}\right)^{0.4924}-1.9011}\right) \\
-0.1571 \exp \left(-0.0474 \vartheta_{\mathrm{pe}}^{8}\right)+0.8102 \exp \left(-40\left(\vartheta_{\mathrm{pe}}-0.1339\right)\right)\end{array}$ \\
\hline
\end{tabular}

\section{Appendix C}

Table C.1 Boundary conditions

\begin{tabular}{|c|c|}
\hline 1 & $\mathbf{n} \cdot \mathbf{i}_{s}=-i_{a p p}, \mathbf{n} \cdot \mathbf{q}=h_{t}\left(T-T_{a}\right)$ \\
\hline II & $\left.\mathbf{n} \cdot \mathbf{i}_{s}\right|_{I_{+}}=\left.\mathbf{n} \cdot \mathbf{i}_{s}\right|_{I_{I}},\left.\mathbf{n} \cdot \mathbf{q}\right|_{I_{+}}=\left.\mathbf{n} \cdot \mathbf{q}\right|_{\|_{I}}, \mathbf{n} \cdot \mathbf{i}_{l}=\mathbf{n} \cdot \mathbf{N}_{l}=\mathbf{0}$ \\
\hline III & $\mathbf{n} \cdot \mathbf{i}_{s}=0,\left.\mathbf{n} \cdot \mathbf{q}\right|_{\mathrm{III}_{+}}=\left.\mathbf{n} \cdot \mathbf{q}\right|_{\mathrm{III}}$ \\
\hline IV, V & $\mathbf{n} \cdot \mathbf{i}_{s}=0(I V), \mathbf{n} \cdot \mathbf{i}_{l}=0(V), \mathbf{n} \cdot \mathbf{q}=0$ \\
\hline VI & $\mathbf{n} \cdot \mathbf{i}_{s}=0,\left.\mathbf{n} \cdot \mathbf{i}_{1}\right|_{\mathrm{V}_{+}}=\left.\mathbf{n} \cdot \mathbf{i}_{/}\right|_{\mathrm{V}_{1}},\left.\mathbf{n} \cdot \mathbf{q}\right|_{\mathrm{V}_{+}}=\left.\mathbf{n} \cdot \mathbf{q}\right|_{\mathrm{VI}_{1}},\left.\mathbf{n} \cdot \mathbf{N _ { l }}\right|_{\mathrm{V}_{+}}=\left.\mathbf{n} \cdot \mathbf{N}_{/}\right|_{\mathrm{V}_{1}}$ \\
\hline VII & $\varphi_{s}=0, \mathbf{n} \cdot \mathbf{q}=h_{t}\left(T-T_{a}\right)$ \\
\hline
\end{tabular}

Table C.2 Initial conditions

\begin{tabular}{|l|}
\hline$c_{s}^{\text {surf }}=c_{s}^{\text {avg }}=c_{s}^{0}$ \\
\hline$c_{l}=c_{l}^{0}$ \\
\hline$\varphi_{s}= \begin{cases}0 & (\mathrm{ne}, \mathrm{cc}(-)) \\
\varphi_{s}^{0} & (\mathrm{pe}, \mathrm{cc}(+))\end{cases}$ \\
$\varphi_{l}=\varphi_{l}^{0}(\mathrm{ne}, \mathrm{pe}, \mathrm{el})$ \\
\hline$T=T_{0}$ \\
\hline
\end{tabular}

(C) 2014 by the authors; licensee IAPC, Zagreb, Croatia. This article is an open-access article distributed under the terms and conditions of the Creative Commons Attribution license (http://creativecommons.org/licenses/by/3.0/) (cc) EY 